\title{
Phenomenological analysis of martensitic transformation in cold-rolled TiNi-base shape memory alloys
}

\author{
S.K. Wu ${ }^{\text {a }}$, H.C. Lin ${ }^{b}, *$ S.H. Chen ${ }^{\mathrm{a}}$ \\ ${ }^{a}$ Institute of Materials Science and Engineering, National Taiwan University, Taipei 106, Taiwan, ROC \\ ${ }^{\mathrm{b}}$ Department of Materials Science, Feng Chia University, Taichung 400, Taiwan, ROC
}

Received 8 March 2000; received in revised form 13 April 2000; accepted 15 May 2000

\begin{abstract}
The martensitic transformation in cold-rolled TiNi-base shape memory alloys has shown that the first reverse martensitic transformation temperature $\left(A_{1}^{*}\right)$ increases with an increasing amount of cold rolling due to the increment of the transformation energy barrier introduced by cold-rolling induced dislocations. Meanwhile, the increment of $A_{1}$ * temperature increases linearly with an increase in the specimen's solution-treated hardness. A phenomenological analysis from the thermodynamic viewpoint of cold-rolling induced dislocations can elucidate these features successfully. After the first reverse transformation, the strengthening effects of retained dislocations on martensitic transformation temperatures follow the equation $M^{*}=T_{\mathrm{O}}-K \Delta \sigma_{\mathrm{ys}}$. The $K$ value is found to be proportional to the specimen's solution-treated hardness, because the harder specimen has the stronger interaction of martensite plates and dislocations induced by cold rolling. The thermal hysteresis of $A_{2}{ }^{*}-M^{*}$, associated with the frictional work during the transformation, does not obviously change in the cold-rolled TiNi-base shape memory alloys. (C) 2001 Elsevier Science B.V. All rights reserved.
\end{abstract}

Keywords: TiNi-base shape memory alloys; Martensitic transformation

\section{Introduction}

TiNi-base alloys are known to be the most important shape memory alloys (SMAs) because of their numerous applications based on the shape memory effect (SME) [1] and pseudo-elasticity (PE) [2,3]. The transformation behavior and mechanical properties in TiNi-base shape memory alloys [2-10] have been extensively studied. These studies have confirmed that the transformation behavior and mechanical properties can be affected by internal stresses induced by various thermal-mechanical treatments, including thermal cycling [11,12], aging treatment in Ni-rich alloys [13-16], and annealing after cold working [17-19]. In our previous articles [19,20], the effects of cold rolling on the martensitic transformation of TiNi binary alloys have been systematically studied. The phenomenon of mechanical-induced martensite stabilization was observed in the cold-rolled TiNi martensite. Both deformed martensite structures and deformation-induced defects are considered to be responsible for the martensite stabilization. After the occurrence of the first reverse martensitic transformation of $\mathrm{B} 19^{\prime} \rightarrow \mathrm{B} 2$, the martensite stabilization dies out and transformation temperatures are depressed by retained dis-

\footnotetext{
* Corresponding author.

E-mail address: hclin@fcu.edu.tw (H.C. Lin).
}

locations in the subsequent thermal cycles. In order to better understand the general phenomena of mechanical-induced martensite stabilization occurring in TiNi-base SMAs, we extend the investigation into the $\mathrm{TiNiX}(\mathrm{X}=\mathrm{Pd}, \mathrm{Zr}, \mathrm{Cu})$ ternary alloys. TiNiCu alloy has been commercialized and TiNiPd, TiNiZr are candidates with potentiality of high temperature shape memory alloys. These TiNiX $(\mathrm{X}=\mathrm{Pd}$, $\mathrm{Zr}, \mathrm{Cu}$ ) ternary alloys exhibit the B19 (or B19') martensite structure at room temperature. Meanwhile, thermodynamic analysis is also used to phenomenologically interpret the martensitic transformation of cold-rolled TiNi-base shape memory alloys.

\section{Experimental procedure}

The conventional tungsten arc-melting technique was employed to prepare the TiNi-base shape memory alloys, including TiNi, TiNiPd, TiNiZr and TiNiCu alloys. The as-melted buttons were homogenized at $1050^{\circ} \mathrm{C}$ in a $7 \times 10^{-6}$ Torr vacuum furnace for $72 \mathrm{~h}$, and then hot rolled into plates with a $5 \mathrm{~mm}$ thickness. Specimens for cold rolling were carefully cut from the plates with a low-speed diamond saw. These specimens were solution-treated at $800^{\circ} \mathrm{C}$ for $2 \mathrm{~h}$ and then quenched in water. After solution treatment, some specimens were cold-rolled at room 


\begin{tabular}{|c|c|}
\hline \multicolumn{2}{|c|}{ Nomenclature } \\
\hline$A_{1}{ }^{*}$ & $\begin{array}{l}\text { reverse martensitic transformation } \\
\text { temperatures for the first heating cycle } \\
\text { in the DSC measurement }\left({ }^{\circ} \mathrm{C}\right)\end{array}$ \\
\hline$A_{1(\mathrm{CR})}{ }^{*}$ & $\begin{array}{l}\text { the first reverse martensitic transformation } \\
\text { temperature in cold-rolled TiNi-base shape } \\
\text { memory alloys }\left({ }^{\circ} \mathrm{C}\right)\end{array}$ \\
\hline$A_{2}{ }^{*}$ & $\begin{array}{l}\text { reverse martensitic transformation } \\
\text { temperatures for the second heating } \\
\text { cycle in the DSC measurement }\left({ }^{\circ} \mathrm{C}\right)\end{array}$ \\
\hline$A_{\mathrm{s}}$ & $\begin{array}{l}\text { reverse martensitic transformation start } \\
\text { temperature }\left({ }^{\circ} \mathrm{C}\right)\end{array}$ \\
\hline B2 & cubic structure \\
\hline B19 & orthorhombic structure \\
\hline $\mathrm{B} 19^{\prime}$ & monoclinic structure \\
\hline$E$ & $\begin{array}{l}\text { the accumulated dislocation energy } \\
\text { per unit volume }\end{array}$ \\
\hline$f^{2}$ & the square of resonant frequency \\
\hline $\mathrm{HD}_{0}$ & specimen's solution-treated hardness \\
\hline \multicolumn{2}{|l|}{$K, K^{\prime}, K_{\mathrm{b}}$} \\
\hline \multicolumn{2}{|l|}{$c_{1}, c_{2}, c_{3}$} \\
\hline$c_{4}, c_{5}, p, q$ & constants \\
\hline$M^{*}$ & $\begin{array}{l}\text { forward martensitic transformation } \\
\text { temperatures in the DSC measurements }\left({ }^{\circ} \mathrm{C}\right)\end{array}$ \\
\hline$M_{\mathrm{s}}$ & $\begin{array}{l}\text { forward martensitic transformation } \\
\text { start temperature }\left({ }^{\circ} \mathrm{C}\right)\end{array}$ \\
\hline$P$ & pressure \\
\hline$T_{0}$ & equilibrium temperature $\left({ }^{\circ} \mathrm{C}\right)$ \\
\hline$T_{\mathrm{m}-\mathrm{p}}$ & $\begin{array}{l}\text { transformation temperature from martensite } \\
\text { to parent phase }\end{array}$ \\
\hline$T_{\mathrm{p}-\mathrm{m}}$ & $\begin{array}{l}\text { transformation temperature from parent } \\
\text { phase to martensite }\end{array}$ \\
\hline$V$ & specimen's volume \\
\hline$W_{\text {fr }}$ & irreversible frictional work \\
\hline \multicolumn{2}{|c|}{ Greek symbols } \\
\hline$\Delta A_{1}{ }^{*}$ & $\begin{array}{l}\text { increment of } A_{1}{ }^{*} \text { temperature due to } \\
\text { cold rolling }\end{array}$ \\
\hline$\Delta G$ & Gibbs free energy change \\
\hline$\Delta G_{1}$ & $\begin{array}{l}\text { Gibbs free energy changes in as-quenched } \\
\text { TiNi-base shape memory alloys }\end{array}$ \\
\hline$\Delta G_{2}$ & $\begin{array}{l}\text { Gibbs free energy changes in cold-rolled } \\
\text { TiNi-base shape memory alloys }\end{array}$ \\
\hline$\Delta G_{\mathrm{av}}$ & available chemical energy change \\
\hline$\Delta G_{\mathrm{ch}}$ & available chemical free energy change \\
\hline$\Delta G_{\mathrm{d}}$ & $\begin{array}{l}\text { the increased transformation energy } \\
\text { barrier due to the cold-rolled dislocations }\end{array}$ \\
\hline$\Delta G_{\mathrm{el}}$ & reversible elastic energy \\
\hline$\Delta H$ & enthalpy change \\
\hline$\Delta H_{\mathrm{c}}$ & $\begin{array}{l}\text { transformation heat of forward martensitic } \\
\text { transformation in the DSC } \\
\text { measurement }\left(\mathrm{Jg}^{-1}\right)\end{array}$ \\
\hline$\Delta H_{\mathrm{h}}$ & $\begin{array}{l}\text { transformation heat of reverse martensitic } \\
\text { transformation in the DSC measurement } \\
\left(\mathrm{Jg}^{-1}\right)\end{array}$ \\
\hline
\end{tabular}

\begin{tabular}{|ll|}
\hline$\Delta S$ & entropy change \\
$\Delta U$ & internal energy change \\
$\Delta U_{\mathrm{d}}$ & the increased internal energy due to the \\
& cold-rolled dislocations \\
$\Delta V$ & volume change \\
$\Delta \sigma_{\mathrm{ys}}$ & increased yielding stress due to the \\
& cold-rolled dislocations \\
$\mu$ & shear modulus \\
$\sigma_{\mathrm{ys}}$ & yielding stress \\
$\tau$ & shear stress \\
\hline
\end{tabular}

temperature to a preset thickness reduction and then subjected to the DSC measurement, hardness test and internal friction test. A Du Pont 9990 thermal analyzer, equipped with a quantitative scanning system 910 DSC cell and cooling accessory LNCA II, was used to run controlled heating and cooling cycles on samples encapsulated in an aluminum pan. Temperatures ranged from -60 to $+400^{\circ} \mathrm{C}$ with a cooling/heating rate of $10^{\circ} \mathrm{C} \mathrm{min}^{-1}$. Heats of transformation $(\Delta H)$, though an error of about $10 \%$ may be expected with the DSC measurements, were automatically calculated from the areas under the DSC peaks with the equipment software packages. Specimens for a hardness test were mechanically polished and then measured in the Vickers microhardness tester with a $1000 \mathrm{~g}$ load at room temperature. For each specimen, the hardness value, Hv, was averaged from at least five test readings. The details of equipment and specimens used for the internal friction test were described in our previous paper [13].

\section{Experimental results}

\subsection{DSC measurements of cold-rolled $T i_{50} N i_{20} P d_{30}$ alloys}

Fig. 1(a)-(c) shows the results of DSC measurement for the as-quenched, 10 and $20 \%$ cold rolled $\mathrm{Ti}_{50} \mathrm{Ni}_{20} \mathrm{Pd}_{30}$ alloys, respectively. In Fig. 1, the subscripts " 1 " and " 2 " of reverse transformation peak temperatures, $A_{1}{ }^{*}$ and $A_{2}{ }^{*}$, indicate, respectively, the first and second heating cycle for each specimen just after the cold rolling. In Fig. 1(a), the heating curve shows that the $\mathrm{B} 19 \rightarrow \mathrm{B} 2$ reverse transformation is an endothermic reaction with $\Delta H_{\mathrm{h} 1}=24.49 \mathrm{~J} \mathrm{~g}^{-1}$ and $A_{1}{ }^{*}=240^{\circ} \mathrm{C}$. The cooling curve of Fig. 1(a) shows that the $\mathrm{B} 2 \rightarrow \mathrm{B} 19$ transformation is an exothermic reaction with $\Delta H_{\mathrm{c}}=23.41 \mathrm{~J} \mathrm{~g}^{-1}$ and $M^{*}=216^{\circ} \mathrm{C}$. In Fig. 1(b), $A_{1}{ }^{*}$ appears at $276^{\circ} \mathrm{C}$ on the first heating cycle from room temperature to $400^{\circ} \mathrm{C}, M^{*}$ appears at $208^{\circ} \mathrm{C}$ on the following cooling cycle from 400 to $100^{\circ} \mathrm{C}$, and $A_{2}{ }^{*}$ appears at $230^{\circ} \mathrm{C}$ on the heating cycle from 100 to $400^{\circ} \mathrm{C}$. In Fig. $1(\mathrm{c}), A_{1}{ }^{*}$ appears at $313^{\circ} \mathrm{C}$ on the first heating cycle from room temperature to $450^{\circ} \mathrm{C}, M^{*}$ appears at $192^{\circ} \mathrm{C}$ on the following cooling cycle from 450 to $100^{\circ} \mathrm{C}$, and $A_{2}{ }^{*}$ appears at $220^{\circ} \mathrm{C}$ on the heating cycle from 100 to $450^{\circ} \mathrm{C}$. In Fig. 1(a)-(c), 


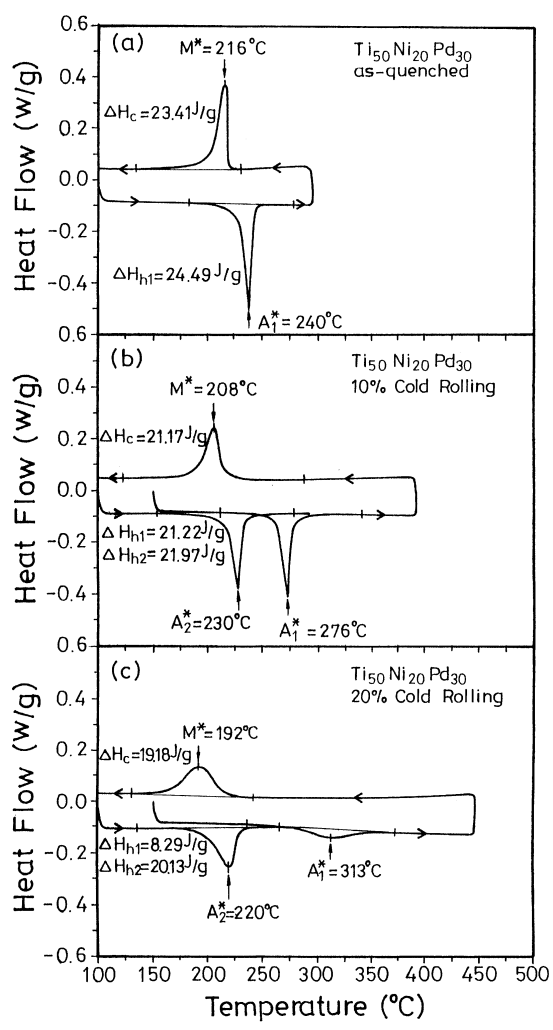

Fig. 1. DSC curves for the $\mathrm{Ti}_{50} \mathrm{Ni}_{20} \mathrm{Pd}_{30}$ alloy: (a) as-quenched specimen; (b) $10 \%$ cold-rolled specimen; (c) $20 \%$ cold-rolled specimen.

one can find that not only the positions of the peaks but also their shapes change significantly with the amount of cold rolling and with cycling. The DSC curves for 5, 15 and $30 \%$ cold-rolled specimens are all similar to those shown in Fig. 1(b) and (c), except for the difference of peak temperatures, peak shapes and $\Delta H$ values, and therefore are omitted in this paper. The detailed data of DSC results, including peak temperatures and $\Delta H$ values, for the $\mathrm{Ti}_{50} \mathrm{Ni}_{20} \mathrm{Pd}_{30}$ alloys with $0-30 \%$ cold rolling are summarized in Table 1 . The data of transformation peak temperatures vs. cold rolling in Table 1 are also plotted in Fig. 2. In Fig. 2, the $A_{1}{ }^{*}$ temperature increases significantly, but $A_{2}{ }^{*}$ and $M^{*}$ temperatures decrease slightly with an increase in cold rolling, and these characteristics are discussed in Section 4.



Fig. 2. Transformation peak temperatures vs. amount of cold rolling for the $\mathrm{Ti}_{50} \mathrm{Ni}_{20} \mathrm{Pd}_{30}$ alloys.

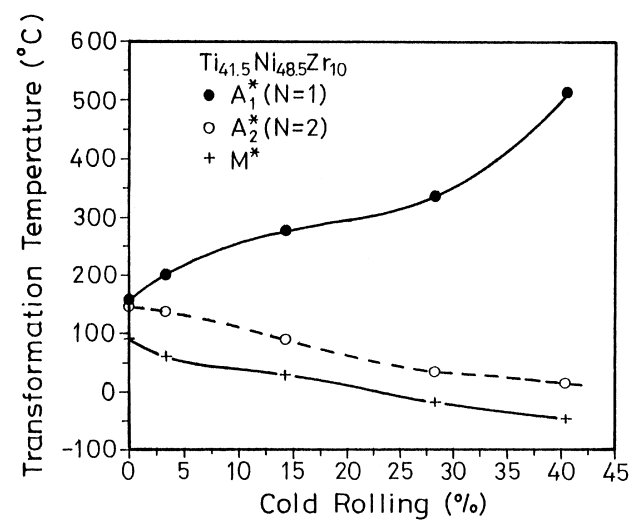

Fig. 3. Transformation peak temperatures vs. amount of cold rolling for the $\mathrm{Ti}_{41.5} \mathrm{Ni}_{48.5} \mathrm{Zr}_{10}$ alloys.

\subsection{Comparison of transformation behaviors in cold-rolled TiNi-base shape memory alloys}

To better understand the general effects of cold rolling on the TiNi-base shape memory alloys, the cold-rolled TiNi binary and $\mathrm{TiNiX}(\mathrm{X}=\mathrm{Zr}, \mathrm{Cu})$ ternary alloys have also been investigated in this study. The transformation behaviors in these cold-rolled alloys are similar to those shown in Figs. 1 and 2 for the cold-rolled $\mathrm{Ti}_{50} \mathrm{Ni}_{20} \mathrm{Pd}_{30}$ alloy. For example, Fig. 3 shows the transformation peak temperatures vs. the

Table 1

DSC measurements of thermal properties for $\mathrm{Ti}_{50} \mathrm{Ni}_{20} \mathrm{Pd}_{30}$ alloy at various amounts of cold rolling

\begin{tabular}{|c|c|c|c|c|c|c|}
\hline $\mathrm{CR}^{\mathrm{a}}(\%)$ & $A_{1}{ }^{*}\left({ }^{\circ} \mathrm{C}\right)$ & $\Delta H_{\mathrm{h} 1}\left(\mathrm{Jg}^{-1}\right)$ & $A_{2}{ }^{*}\left({ }^{\circ} \mathrm{C}\right)$ & $\Delta H_{\mathrm{h} 2}\left(\mathrm{Jg}^{-1}\right)$ & $M^{*}\left({ }^{\circ} \mathrm{C}\right)$ & $\Delta H_{\mathrm{c}}\left(\mathrm{Jg}^{-1}\right)$ \\
\hline 0 & 240 & 24.49 & 240 & 24.49 & 216 & 23.41 \\
\hline 5 & 250 & 22.96 & 232 & 23.25 & 211 & 22.13 \\
\hline 10 & 276 & 21.22 & 230 & 21.97 & 208 & 21.17 \\
\hline 15 & 301 & 12.43 & 224 & 20.29 & 200 & 20.07 \\
\hline 20 & 313 & 8.29 & 220 & 20.13 & 192 & 19.18 \\
\hline 30 & 404 & 7.58 & 215 & 20.15 & 186 & 18.73 \\
\hline
\end{tabular}

${ }^{\text {a }} \mathrm{CR}$ means cold rolling or thickness reduction amounts. 


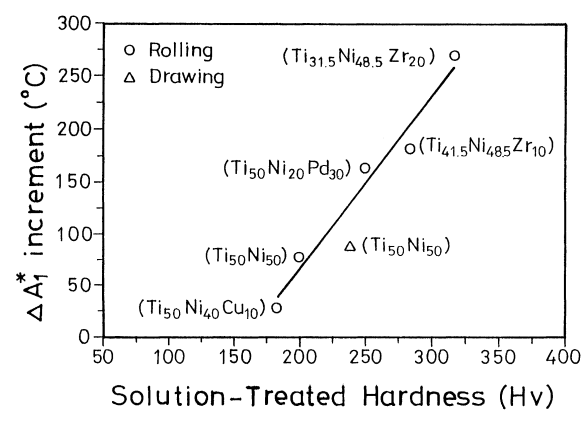

Fig. 4. The increment of $A_{1}{ }^{*}$ temperature $\left(\Delta A_{1}{ }^{*}\right)$ by $30 \%$ cold rolling as a function of specimen's solution-treated hardness for the cold-rolled TiNi-base alloys.

amount of cold rolling for the $\mathrm{Ti}_{41.5} \mathrm{Ni}_{48.5} \mathrm{Zr}_{10}$ alloy. The variation tendency of transformation peak temperatures vs. cold rolling is similar to that shown in Fig. 2 for the $\mathrm{Ti}_{50} \mathrm{Ni}_{20} \mathrm{Pd}_{30}$ alloy. However, some important differences for these TiNi-base shape memory alloys, which originate from the effects of cold rolling, are compared in Figs. 4 and 5. Fig. 4 shows the increment of $A_{1}{ }^{*}$ temperature $\left(\Delta A_{1}{ }^{*}\right)$ by $30 \%$ cold rolling as a function of the specimen's solution-treated hardness $\left(\mathrm{HD}_{0}\right)$ for these TiNi-base alloys. Here, $\Delta A_{1}{ }^{*}$ indicates the difference between $A_{1}{ }^{*}$ temperatures with and without cold rolling, and $\mathrm{HD}_{0}$ is the hardness tested at room temperature for specimens with solution treatment at $800^{\circ} \mathrm{C}$ for $2 \mathrm{~h}$. The $\mathrm{HD}_{0}$ is a material intrinsic property, which would not be affected by the amount of cold rolling. In Fig. 4, $\Delta A_{1}{ }^{*}$ is found to increase linearly with an increase in the specimen's solution-treated hardness for various TiNi-base alloys. It is worthy to mention that the linear relationship between $\Delta A_{1}{ }^{*}$ and specimen's solution-treated

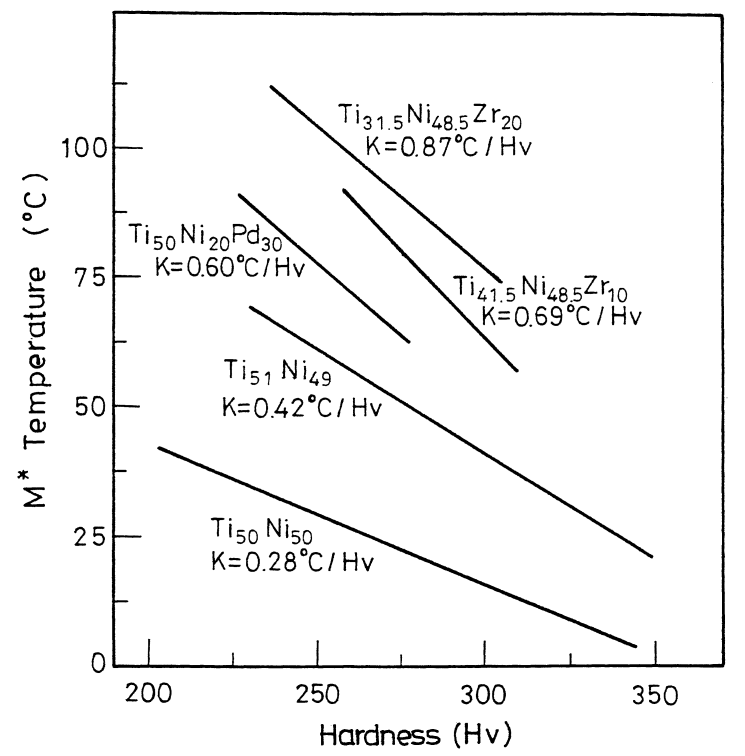

Fig. 5. The relationship between $M^{*}$ temperatures and specimen hardness for the TiNi-base alloys which have been subjected to various amounts of cold rolling and the first reverse martensitic transformation. hardness can also be observed for other amounts of cold rolling. Fig. 5 shows the relationship between $M^{*}$ temperature and specimen hardness for the TiNi-base alloys which have been subjected to various amounts of cold rolling and the first reverse martensitic transformation. In Fig. 5, $M^{*}$ temperature is found to decrease with increasing specimen hardness for each kind of TiNi-base alloy. The characteristics shown in Figs. 4 and 5 are also discussed in Section 4.

\section{Discussion}

\subsection{Thermodynamic analysis of martensitic transformation in cold-rolled TiNi-base shape memory alloys}

From Figs. 1 and 2, one can find that $A_{1}{ }^{*}$ increases significantly, but $A_{2}{ }^{*}$ and $M^{*}$ temperatures decrease slightly with an increasing amount of cold rolling for the $\mathrm{Ti}_{50} \mathrm{Ni}_{20} \mathrm{Pd}_{30}$ alloy. The above phenomenon is regarded as the mechanically induced martensite stabilization, the same behavior as reported in the $\mathrm{Ti}_{50} \mathrm{Ni}_{50}$ alloy [19]. According to TEM observations of cold-rolled $\mathrm{Ti}_{50} \mathrm{Ni}_{50}$ [19] and $\mathrm{Ti}_{50} \mathrm{Ni}_{20} \mathrm{Pd}_{30}$ [21] alloys, a variety of deformed martensite structures and deformation-induced defects are observed when the specimens have been subjected to cold rolling. These deformed martensite structures and deformation-induced defects are expected to inhibit the reverse martensitic transformation by imposing a friction stress on the martensite/parent interfaces. Therefore, the reverse martensitic transformation temperatures, $A_{1}{ }^{*}$, must shift to higher ones since the transformation requires additional energy to overcome the increased friction stress.

Based on thermodynamic analysis [22-25], the thermoelastic behavior is a condition of local balance between chemical and non-chemical forces. Chemical forces arise from the difference in Gibbs free energy between parent phase and martensite, and act as a driving force promoting the phase with lower energy at each temperature. Non-chemical forces can be acknowledged to arise from two different sources, namely, the elastic energy and frictional work. The elastic energy is stored in the specimens during the transformation from parent phase to martensite, and reversibly recovered during the reverse transformation. The frictional work is mainly devoted to overcome frictional barriers opposing interfacial motion either during growth or during shrinkage of the martensite plates. The net driving force or available chemical free energy difference $\left(\Delta G_{\mathrm{av}}\right)$ per mole of the moving plates can be explicitly written as follows:

$\Delta G_{\mathrm{av}}=-\Delta G_{\mathrm{ch}}+\Delta G_{\mathrm{el}}+W_{\mathrm{fr}}$

where $\Delta G_{\mathrm{ch}}, \Delta G_{\mathrm{el}}$ and $W_{\mathrm{fr}}$ represent the chemical free energy change, stored elastic energy and frictional work, respectively. The increases in $\Delta G_{\mathrm{el}}$ or $W_{\mathrm{fr}}$ will both cause $M_{\mathrm{S}}$ (transformation temperature from parent phase to martensite, or $M^{*}$ here) to decrease, while $A_{\mathrm{s}}$ (transformation temperature from martensite to parent phase, or $A^{*}$ here) 
decreases with increasing $\Delta G_{\mathrm{el}}$ but increases with increasing $W_{\mathrm{fr}}$. Meanwhile, $W_{\mathrm{fr}}$ will cause the transformation hysteresis.

Titchener and Bever [26] reported that cold rolling will raise the internal energy due to the introduction of a new phase, lattice strain or crystal imperfections within the material. These deformed features will also have effects on the nucleation and growth of farther martensitic transformations, as reported in the thermoelastic $\mathrm{Cu}-\mathrm{Zn}-\mathrm{Al}$ alloys [27-29]. As mentioned above, the deformed martensite structures and deformation-induced defects exist in the cold-rolled TiNi-base shape memory alloys. We are interested to understand how these deformed features affect the Gibbs free energy change during the subsequent reverse and forward martensitic transformations. In assuming that the twinned martensite plates in TiNi-base shape memory alloys are created by a pole mechanism [30,31], it is believed that a high density of twin dislocations exist around the interfaces of the twinned martensite. By neglecting the minor effects of point defects and considering that the movement of twinned martensite plates is caused by the movement of twin dislocations, the variation of available chemical free energy change associated with the martensitic transformations in the cold-rolled TiNi-base shape memory alloys can be simply discussed with the effects of dislocations. The energy difference of the dislocations, when embedded in the parent B2 phase or martensite, will affect their relative stability and therefore the transformation temperatures.

Consider the thermodynamic formula

$\Delta H=\Delta U+P \Delta V$

where $\Delta H$ is the enthalpy change, $\Delta U$ the internal energy change, $P$ the pressure, and $\Delta V$ is the volume change associated with the martensitic transformation. For the thermoelastic TiNi-base shape memory alloys, the transformation volume change is quite small. Hence, by neglecting $P \Delta V$, Eq. (2) becomes

$\Delta H=\Delta U$

Cottrell [32] evaluated the entropy change $\Delta S$ by using Boltzmann's equation and found that the $\Delta S$ associated with the formation or movement of one dislocation is only about $0.1 \mathrm{eV}$, which is far below the dislocation strain energy. Hence, the Gibbs free energy change for the martensitic transformations of cold-rolled TiNi-base shape memory alloys can be simply expressed as follows:

$$
\Delta G=\Delta H-T \Delta S \fallingdotseq \Delta H=\Delta U
$$

As mentioned above, the cold rolling on TiNi-base shape memory alloys will introduce deformed martensite structures and crystal defects. These deformed features must be overcome during the subsequent reverse and forward transformations, and hence the transformation energy barrier will be increased. This increased energy barrier resulting from cold rolling, $\Delta G_{\mathrm{d}}$, is considered to be proportional to the increased internal energy due to cold rolling, $\Delta U_{\mathrm{d}}$, which comes from the accumulated dislocation energy introduced by cold rolling. Namely,

$\Delta G_{\mathrm{d}}=K_{\mathrm{b}} \Delta U_{\mathrm{d}}$

where $K_{\mathrm{b}}$ is a constant. The accumulated dislocation energy in a plastic deformed material is reported [33] to be

$E \fallingdotseq 25 \frac{\tau^{2}}{\mu}$

where $E$ is the accumulated dislocation energy per unit volume, $\tau$ the shear stress, and $\mu$ is the shear modulus. During plastic deformation, the applied shear stress $\tau$ must exceed the yielding shear stress $\tau_{\text {ys }}$, i.e.,

$\tau=\tau_{\mathrm{ys}}+\tau^{\prime}=K^{\prime} \sigma_{\mathrm{ys}}+\tau^{\prime}$

where $\tau^{\prime}$ is the exceeding amount of shear stress and $K^{\prime}$ is the transformation factor between the yielding shear stress $\tau_{\text {ys }}$ and the yielding stress $\sigma_{\text {ys }}$. According to the empirical formula [34] of yielding stress $\sigma_{\mathrm{ys}}$ and hardness $\mathrm{HD}_{0}$ for the solution-treated specimens,

$\sigma_{\mathrm{ys}}=\frac{1}{3} \mathrm{HD}_{0}$

and using Eqs. (7) and (8), Eq. (6) becomes

$E \fallingdotseq 25 \frac{\tau^{2}}{\mu}=\frac{25\left[\frac{1}{3} K^{\prime} \mathrm{HD}_{0}+\tau^{\prime}\right]^{2}}{\mu}$

According to the vibration theory, the shear modulus $\mu$ is proportional to the square of the resonant frequency $f$, namely, $\mu \propto f^{2}$. In our previous paper [35], the resonant frequency $f$ and specimen's solution-treated hardness $\mathrm{HD}_{0}$ for TiNi-base shape memory alloys have been measured. Based on the experimental data in [35], the square of resonant frequency $f^{2}$ at room temperature is plotted as a function of $\mathrm{HD}_{0}$ in Fig. 6 for several TiNi-base shape memory alloys. From Fig. 6, a linear relationship between $f^{2}$ and $\mathrm{HD}_{0}$ is observed. Hence, we can derive that $\mu$ is proportional to the specimen's solution-treated hardness $\mathrm{HD}_{0}$, namely,

$\mu=c_{1} \mathrm{HD}_{0}+c_{2}$

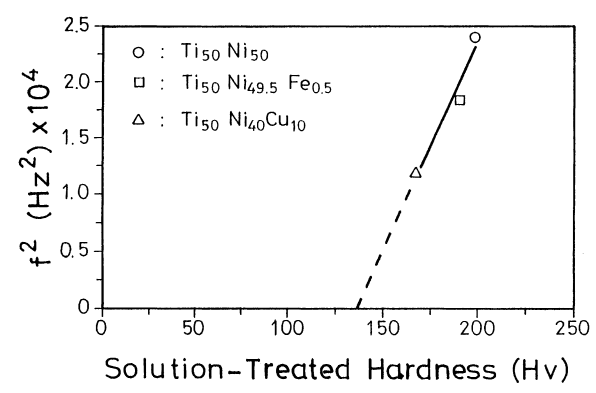

Fig. 6. The relationship between the square of resonant frequency $\left(f^{2}\right)$ and specimen's solution-treated hardness $\left(\mathrm{HD}_{0}\right)$ for the TiNi-base shape memory alloys. 
where $c_{1}$ and $c_{2}$ are constants. Therefore,

$$
\begin{aligned}
E & \fallingdotseq \frac{25\left[\frac{1}{3} K^{\prime} \mathrm{HD}_{0}+\tau^{\prime}\right]^{2}}{\mu} \fallingdotseq \frac{25\left[\frac{1}{3} K^{\prime} \mathrm{HD}_{0}+\tau^{\prime}\right]^{2}}{\left[c_{1} \mathrm{HD}_{0}+c_{2}\right]} \\
& \fallingdotseq c_{3} \mathrm{HD}_{0}+c_{4}+\frac{c_{5}}{\left[c_{1} \mathrm{HD}_{0}+c_{2}\right]} \fallingdotseq c_{3} \mathrm{HD}_{0}+c_{4}
\end{aligned}
$$

where $c_{3}, c_{4}$, and $c_{5}$ are also constants. In this study, the plastic deformation was carried out by a multiple passage. The amount of cold rolling in every passage was quite small, and thus $\tau^{\prime} \ll \sigma_{\mathrm{ys}}$ is expected. Therefore, the constant $c_{5}$ in Eq. (11), being related to the square of $\tau^{\prime}$, can be reasonably omitted. From Eq. (11), the raised transformation energy barrier due to cold rolling in Eq. (5) can be derived to be

$\Delta G_{\mathrm{d}}=K_{\mathrm{b}} \Delta U_{\mathrm{d}}=K_{\mathrm{b}} E V=K_{\mathrm{b}} V\left[c_{3} \mathrm{HD}_{0}+c_{4}\right]$

where $V$ is the specimen's volume. Eq. (12) indicates that $\Delta G_{\mathrm{d}}$ is proportional to the specimen's solution-treated hardness $\mathrm{HD}_{0}$ of TiNi-base shape memory alloys.

\subsection{A phenomenological discussion of martensite stabilization in cold-rolled TiNi-base shape memory alloys}

According to the thermodynamic analysis in Section 4.1 , the net driving force or available chemical free energy change in cold-rolled TiNi-base shape memory alloys can be expressed as follows:

$$
\Delta G_{\mathrm{av}}=-\Delta G_{\mathrm{ch}}+\Delta G_{\mathrm{el}}+W_{\mathrm{fr}}+\Delta G_{\mathrm{d}}
$$


where $\Delta G_{\mathrm{d}}$ is the Gibbs free energy change introduced by cold-rolling induced dislocations. The phenomenon of martensite stabilization in cold-rolled TiNi-base shape memory alloys is illustrated in Fig. 7(a)-(d). In Fig. 7(a), the Gibbs free energies of martensite and parent phase at the equilibrium temperature $T_{0}$ are equal. However, to overcome the transformation energy barrier, the reverse martensitic transformation temperatures have to shift to higher ones. The higher the transformation energy barrier, the higher is the transformation temperature. In Fig. 7(b), the dash and solid lines indicate the transformation energy barriers for the as-quenched martensite with and without cold rolling, respectively, to transform to the parent phase at $T=T_{0}$. As shown in Fig. 7(b), more driving force is necessary for the cold-rolled martensite to transform to the parent phase. At $T=A_{1}{ }^{*}$, the reverse transformation temperature of the as-quenched martensite, there is not enough driving force to overcome the energy barrier to cause the reverse transformation of cold-rolled martensite, as shown in Fig. 7(c). Then, the transformation temperature has to shift to a higher one $\left(A_{1(\mathrm{CR})}{ }^{*}\right)$ to start the first reverse transformation of cold-rolled martensite, as shown in Fig. 7(d). The greater the amount of cold rolling, the greater the transformation energy barrier $\Delta G_{\mathrm{d}}$, i.e., $\left(\Delta G_{2}-\Delta G_{1}\right)$ increases (Fig. 7(a)). Hence the $A_{1(\mathrm{CR})}{ }^{*}$ temperature should increase with an increasing amount of cold rolling. From Fig. 7(a), one can find that

$\frac{\left[A_{1}{ }^{*}-T_{0}\right]}{\left[A_{1(\mathrm{CR})}{ }^{*}-T_{0}\right]}=\frac{\Delta G_{1}}{\Delta G_{2}}$

(b)

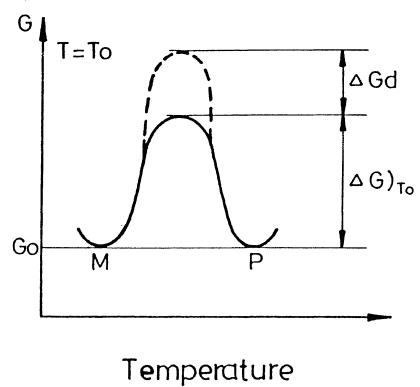

(d)

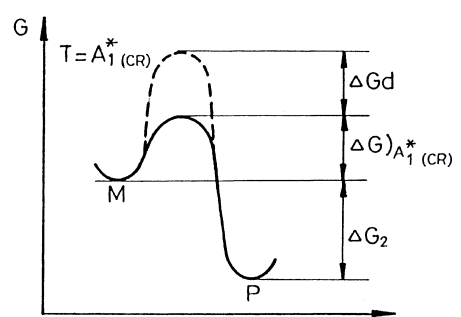

Temperature

$\left.\because \Delta \mathrm{G})_{\mathrm{A}^{*}}+\Delta \mathrm{G}_{\mathrm{d}}=\Delta \mathrm{G}\right)_{\mathrm{T}_{0}}$

$\therefore$ The reverse transformation occurs at $\mathrm{T}=\mathrm{A}_{1(\mathrm{CR})}{ }^{*}$.

Fig. 7. The illustrated diagrams of Gibbs free energy vs. temperature showing the increase of transformation energy barrier and the raise of $A_{1}{ }^{*}$ temperature for the cold-rolled TiNi-base alloys: (a) undeformed TiNi-base alloys; (b) cold-rolled TiNi-based alloys at $T=T_{0}$; (c) cold-rolled TiNi-based alloys at $T=A_{1}{ }^{*}$; (d) cold-rolled TiNi-based alloys at $T=A_{1(\mathrm{CR})}{ }^{*}$. 


$$
\begin{aligned}
& \Rightarrow A_{1(\mathrm{CR})}{ }^{*}-A_{1}{ }^{*}=\frac{\left[A_{1}{ }^{*}-T_{0}\right]\left[\Delta G_{2}-\Delta G_{1}\right]}{\Delta G_{1}} \\
& =\frac{\left[A_{1}^{*}-T_{0}\right]\left[\Delta G_{\mathrm{d}}\right]}{\Delta G_{1}} \\
& \Rightarrow \Delta A_{1}{ }^{*}=A_{1(\mathrm{CR})}{ }^{*}-A_{1}{ }^{*}=\frac{\left[A_{1}{ }^{*}-T_{0}\right]\left[\Delta G_{\mathrm{d}}\right]}{\Delta G_{1}}
\end{aligned}
$$

The specimen's chemical composition does not change during cold rolling, and hence $A_{1}{ }^{*}, T_{0}$ and $\Delta G_{1}$ remain constant. Thus, Eq. (16) indicates a proportional relationship between $\Delta A_{1}{ }^{*}$ and $\Delta G_{\mathrm{d}}$. Combining Eqs. (12) and (16), one can obtain

$\Delta A_{1}^{*}=\frac{\left[A_{1}^{*}-T_{0}\right] K_{\mathrm{b}} V\left[c_{3} \mathrm{HD}_{0}+c_{4}\right]}{\Delta G_{1}}=p \mathrm{HD}_{0}+q$

where $p$ and $q$ are constants. Eqs. (12) and (17) indicate that, for the TiNi-base shape memory alloys, the higher the specimen's solution-treated hardness, the higher the increment of transformation energy barrier $\Delta G_{\mathrm{d}}$, and hence the higher the increment of $A_{1}$ * temperature. Namely, for the cold-rolled TiNi-base shape memory alloys, $\Delta A_{1}{ }^{*}$ increases with an increase in the specimen's solution-treated hardness. This phenomenon is consistent with the experimental results shown in Fig. 4.

\subsection{Strengthening effects of cold rolling on martensitic transformation temperatures of TiNi-base shape memory alloys}

In Fig. 2, $M^{*}$ and $A_{2}{ }^{*}$ temperatures are found to decrease with an increase in cold rolling for the $\mathrm{Ti}_{50} \mathrm{Ni}_{20} \mathrm{Pd}_{30}$ alloy. The decrease of these transformation temperatures is attributed to the retained dislocations after the first reverse martensitic transformation [19]. Fig. 5 shows the relationship between $M^{*}$ temperatures and specimen hardness $\mathrm{Hv}$ for many cold-rolled TiNi-base shape memory alloys. From Fig. 5, $M^{*}$ temperatures obviously decrease with increasing hardness for each kind of cold-rolled TiNi-base shape memory alloys. This feature can be expressed by the equation $[36,37]$

$M^{*}=T_{0}-K \Delta \sigma_{\mathrm{ys}}$

where the constant $K$ contains the factors of proportionality between the critical shear stress and the yield stress $\Delta \sigma_{\text {ys }}$, the equilibrium temperature $T_{0}$ is a function of the chemical composition, and the yield stress $\Delta \sigma_{y s}$ is regarded as being proportional to the hardness. From Fig. 5, one can find that the $K$ values, namely the slopes of $M^{*}$ temperature vs. hardness curves, are different for various TiNi-base shape memory alloys. The solution-treated hardness of various TiNi-base shape memory alloys and their corresponding $K$ values of cold rolling are summarized in Table 2. From Table 2, one can find that the higher the specimen's solution-treated hardness, the larger the $K$ value. These results indicate that the depression of $M^{*}$ and $A^{*}$
Table 2

The solution-treated hardness and corresponding $K$ values of cold rolling for various TiNi-base shape memory alloys

\begin{tabular}{lll}
\hline Composition (at.\%) & $\begin{array}{l}\text { Solution-treated } \\
\text { hardness }\end{array}$ & $\begin{array}{l}K \text { value (Hv) } \\
\text { rolling) }\end{array}$ \\
\hline $\mathrm{Ti}_{50} \mathrm{Ni}_{50}$ & 200 & 0.28 \\
$\mathrm{Ti}_{51} \mathrm{Ni}_{49}$ & 228 & 0.42 \\
$\mathrm{Ti}_{31.5} \mathrm{Ni}_{48.5} \mathrm{Zr}_{20}$ & 317 & 0.87 \\
$\mathrm{Ti}_{41.5} \mathrm{Ni}_{48.5} \mathrm{Zr}_{10}$ & 285 & 0.68 \\
$\mathrm{Ti}_{50} \mathrm{Ni}_{20} \mathrm{Pd}_{30}$ & 250 & 0.60 \\
\hline
\end{tabular}

${ }^{\text {a }}$ Solution-treated hardness is the hardness tested at room temperature for specimens with no cold rolling.

temperatures by cold rolling is stronger for the alloys with higher solution-treated hardness. These phenomena can be explained as follows.

As mentioned in Section 3.2, if the cold-rolled specimens are subjected to a reverse martensitic transformation, the cold-rolling induced dislocations still remain in the parent phase. These retained dislocations can slightly increase the energy barrier during the subsequent forward martensitic transformation, as illustrated in Fig. 8(a). More driving force is needed for these cold-rolled specimens to transform from parent phase to martensite. Hence, $M^{*}$ temperature must shift to a lower one to start the transformation. However, during this forward martensitic transformation, more elastic energy can be produced and stored in the martensite due to the interaction between dislocations and martensite plates as a result of the movement of the martensite boundary, as illustrated by the dashed line in Fig. 8(b). Namely, the dislocation energy can be changed into elastic energy $\Delta G_{\mathrm{el}}$ and stored in the martensite plates. As mentioned in Section

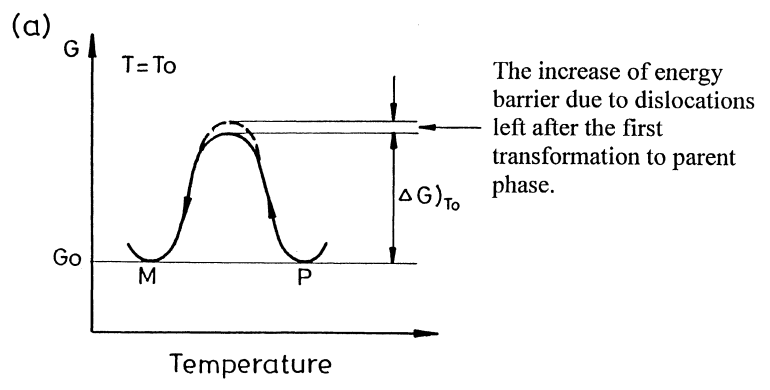

(b)

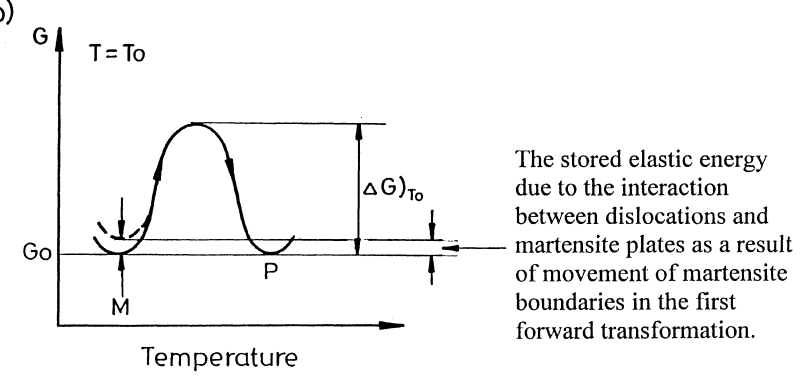

Fig. 8. The illustrated diagrams of Gibbs free energy vs. temperature showing: (a) the variations of transformation energy barrier; (b) stored elastic energy for the cold-rolled TiNi-base alloys after the first reverse martensitic transformation. 
4.1, this stored elastic energy will promote the second reverse transformation and hence the $A_{2} *$ temperature will be lowered. If the specimens are subjected to more cold rolling, more residual dislocations remain in the matrix and more elastic energy is stored in the martensite plates. This feature can elucidate why $A_{2}{ }^{*}$ and $M^{*}$ temperatures monotonously decrease with increasing cold rolling in TiNi-base shape memory alloys. Meanwhile, in Table 2, one can find that the higher the specimen's solution-treated hardness, the larger the $K$ value. This phenomenon is reasonable because the energy barrier increases as a result of the retained dislocations if the specimen has a greater solution-treated hardness, as derived from Eq. (12). In other words, if the specimens have greater solution-treated hardness, the interaction between retained dislocations and martensite plates requires more driving force to cause the movement of martensite/parent interfaces during the martensitic transformations, and hence have a larger $K$ value. Additionally, after carefully examining Figs. 2 and 3, the thermal hysteresis of $A_{2}{ }^{*}-M^{*}$ is found to be nearly the same for various amounts of cold rolling. This indicates that the frictional work $W_{\mathrm{fr}}$, which causes the thermal hysteresis of $A_{2}{ }^{*}-M^{*}$, does not experience an obvious change if the TiNi-base alloys are subjected to cold rolling and a following reverse martensitic transformation.

\section{Conclusions}

The martensitic transformations in cold-rolled TiNi-base shape memory alloys have been systematically studied by using the DSC measurement, a hardness test and an internal friction test. The important conclusions are as follows:

1. The increased transformation energy barrier, $\Delta G_{\mathrm{d}}$, will be induced by cold rolling in the TiNi-base shape memory alloys. The higher the amount of cold rolling, the higher the $\Delta G_{\mathrm{d}}$. Hence the $A_{1}{ }^{*}$ temperature will increase with an increasing amount of cold rolling. Meanwhile, the higher the specimen's solution-treated hardness, the higher the increment of $\Delta G_{\mathrm{d}}$ induced by cold rolling. Therefore, the increment of $A_{1} *$ temperature $\left(\Delta A_{1}{ }^{*}\right)$ increases linearly with increasing specimen's solution-treated hardness. A phenomenological analysis to explain these features, from the thermodynamic viewpoint of cold-rolling induced dislocations, is discussed and has found that these features can be elucidated successfully.

2. After the first reverse transformation of the cold-rolled TiNi-base shape memory alloys, the strengthening effects of retained dislocations on martensitic transformation temperatures follow the equation of $M^{*}=T_{0}-$ $K \Delta \sigma_{\text {ys }}$. The higher the specimen's solution-treated hardness, the larger the $K$ value. This is because the interaction of martensite plates and dislocations induced by cold rolling is stronger for the specimen with greater hardness. The thermal hysteresis of $A_{2}{ }^{*}-M^{*}$ does not experience an obvious change if the TiNi-base shape memory alloys are subjected to various amounts of cold rolling. This means that the frictional work, $W_{\mathrm{fr}}$, does not change much by the cold-rolling induced dislocations in TiNi-base shape memory alloys.

\section{Acknowledgements}

The authors are pleased to acknowledge the financial support of this research by National Science Council (NSC), Republic of China, under the NSC Grant 86-2216-E002-033.

\section{References}

[1] S. Miyazaki, K. Otsuka, Y. Suzuki, Scripta Metall. 15 (1981) 287.

[2] S. Miyazaki, Y. Ohmi, K. Otsuka, Y. Suzuki, Proceedings of ICOMAT-82, J. Phys. 43 (1982) C4-255.

[3] S. Miyasaki, T. Imai, Y. Igo, K. Otsuka, Metall. Trans. A 17 (1986) 115.

[4] G.D. Sandrock, A.J. Perkins, R.F. Hehemann, Metall. Trans. A 2 (1971) 2769.

[5] K. Otsuka, T. Sawamura, K. Shimizu, Phys. Stat. Sol. (a) 5 (1971) 457.

[6] H.C. Ling, R. Kaplow, Metall. Trans. A 12 (1981) 2101.

[7] C.M. Hwang, M. Meichle, M.B. Salamon, C.M. Wayman, Philos. Mag. 47 (1983) 9.

[8] S.K. Wu, C.M. Wayman, Mater. Sci. Eng. 96 (1987) 295.

[9] M. Nishida, C.M. Wayman, T. Honma, Metall. 19 (1986) 99.

[10] C.M. Hwang, C.M. Wayman, Scripta Metall. 17 (1983) 1449.

[11] S. Miyazaki, Y. Igo, K. Otsuka, Acta Metall. 34 (1986) 2045.

[12] T. Tadaki, Y. Nakata, K. Shimazu, Trans. Jpn. Inst. Met. 28 (1987) 883.

[13] S.K. Wu, H.C. Lin, T.S. Chou, Acta Metall. 38 (1990) 95.

[14] M. Nishida, T. Honma, Scripta Metall. 18 (1984) 1293.

[15] M. Nishida, C.M. Wayman, Scripta Metall. 18 (1984) 1389.

[16] S.K. Wu, H.C. Lin, Scripta Metall. Mater. 25 (1991) 1295.

[17] Y. Okamota, H. Hamanaka, F. Miura, H. Tamura, H. Horikawa, Scripta Metall. 22 (1988) 517.

[18] T. Todoroki, H. Tamura, Trans. Jpn. Inst. Met. 28 (1987) 83.

[19] H.C. Lin, S.K. Wu, T.S. Chou, H.P. Kao, Acta Metall. Mater. 39 (1991) 2069.

[20] H.C. Lin, S.K. Wu, Acta Metall. Mater. 42 (1994) 1623.

[21] Y.C. Lo, S.K. Wu, Trans. Mat. Res. Soc. Jpn. 18B (1994) 1029.

[22] R.J. Salzbrenner, M. Cohen, Acta Metall. 27 (1979) 739.

[23] Y. Liu, P.G. McCormick, Acta Metall. Mater. 42 (1994) 2401.

[24] J. Ortin, A. Planes, Acta Metall. 36 (1988) 1873.

[25] P. Wollants, J.R. Roos, L. Delaey, Prog. Mater. Sci. 37 (1993) 227.

[26] A.L. Titchener, M.B. Bever, Progress in Metal Physics, Pergamon Press, New York, 1958, p. 247.

[27] E. Hornbogen, Proceedings of ICOMAT-86, Nara, Japan, 1986, p. 453.

[28] D. Roqueta, F.C. Lovey, M. Sade, Scripta Materialia 34 (1996) 1747.

[29] D. Rios-Jara, G. Guenin, Acta Metall. 35 (1987) 109.

[30] A.H. Cotrell, B.A. Bilby, Philos. Mag. 42 (1951) 573.

[31] J.W. Christian, J. Phys. 12 (1974) C7-65.

[32] A.H. Cottrell, Dislocations and Plastic Flow in Crystals, Section 6, Oxford University Press, NY, 1953.

[33] P. Haasen, Physical Metallurgy, Cambridge University Press, Cambridge, 1978, p. 350.

[34] M.F. Ashby, D.R.H. Jones, Engineering Materials, Cambridge University Press, Cambridge, UK, p. 103.

[35] H.C. Lin, S.K. Wu, Y.C. Chang, Metall. Mater. Trans. A 26 (1995) 851.

[36] E. Hornbogen, Acta Metall. 33 (1985) 595.

[37] S. Eucken, E. Hornbogen, J. Mater. Sci. 19 (1984) 1343. 